\title{
A Potential Participant in Type 2 Diabetes Bone Fragility: TIMP-I at Sites of Osteocyte Lacunar-Canalicular System
}

\author{
Qilin $\mathrm{Pei}^{1, *}$ \\ Jun $\mathrm{Li}^{2, *}$ \\ Pengfei Zhou ${ }^{3, *}$ \\ Jun Zhang (D) \\ Peng Huang' \\ Jingchuan Fan' \\ Zhen Zou (D) \\ $\mathrm{Xi} \mathrm{Li}{ }^{1}$ \\ Bin Wang ${ }^{\prime}{ }^{\prime}$
}

'Institute of Life Sciences, Chongqing Medical University, Chongqing, 400016 , People's Republic of China; ${ }^{2}$ Department of Orthopedic Surgery, Chengdu Fifth People's Hospital, Chengdu, Sichuan Province, 610072, People's Republic of China; ${ }^{3}$ Chongqing Key Laboratory of Oral Diseases and Biomedical Sciences, Stomatological Hospital of Chongqing Medical University, Chongqing, 40II47, People's Republic of China

*These authors contributed equally to this work
Correspondence: Bin Wang; Xi Li Email bwang@cqmu.edu.cn; lixi@shmu. edu.cn

\begin{abstract}
Type 2 diabetes mellitus (T2DM) is associated with an increased risk of bone fracture, but the bone mineral density (BMD) is typically normal or higher in such patients. Because the fracture risk is independent of reduced BMD, bone fragility in T2DM may be partially due to poor bone quality. The mechanisms triggering bone quality abnormalities in T2DM are complex, and include the accumulation of advanced glycation end-products, the increased inflammation, and low bone turnover. Matrix metalloproteinases (MMPs) in bone can hydrolyze the bone matrix. Tissue inhibitors of MMPs (TIMPs) can inhibit the activity of MMPs. Both MMPs and TIMPs participate in mediating bone quality. Among all types of TIMPs, TIMP-1 is mostly reportedly increased in the serum of T2DM patients. Because osteocytes can express TIMP-1, and osteocyte pericellular matrix influences bone quality partially regulated by perilacunar/canalicular remodeling, we hypothesized that TIMP-1 at sites of osteocyte lacunar-canalicular system is involved in T2DM bone fragility.
\end{abstract}

Keywords: bone fragility, lacunar-canalicular system, osteocyte, TIMP-1, type 2 diabetes mellitus

\section{Introduction}

Type 2 diabetes mellitus (T2DM) is associated with an increased risk of fragility bone fractures, despite individuals with T2DM having normal or greater bone mineral density (BMD). ${ }^{1-5}$ This increased fracture risk remains even after accounting for potential confounders such as falls, and it may be partially due to poor bone quality. Bone quality encompasses several bone properties reflecting bone geometry or microarchitecture, and the organization and/or composition of collagen and minerals in the bone matrix. Various mechanisms of bone quality deterioration in T2DM have been reported. Animal model studies indicated that impaired bone quality in T2DM is multifactorial, and includes changes in microarchitecture, abnormal collagen crosslinking, and matrix mineralization. Hunt et $\mathrm{al}^{6}$ investigated several aspects of bone quality in a clinical population of men with and without T2DM, and detected high concentrations of advanced glycation end-products and altered mineral maturity in femoral neck cancellous bone from T2DM men. Karim et $\mathrm{al}^{7}$ reported that cortical bone had worse indentation properties and higher advanced glycation end-products in the proximal femurs of adults with T2DM.

Apart from changes in bone extracellular matrix (ECM) at the tissue level in T2DM, Eckhardt et $\mathrm{al}^{8}$ reported that accelerated osteocyte senescence may be 
involved in the skeletal fragility observed in the high-fat diet/streptozotocin mouse model of T2DM. Several prior studies indicate that the osteocyte network is altered in different diabetes models. ${ }^{9-11}$ Osteocytes are the most abundant cells in bone, and have a large number of dendritic cell processes through which osteocytes communicate with the surrounding osteocytes and bone surface cells such as osteoblasts and osteoclasts. ${ }^{12}$ Osteocytes and their cell processes reside in a mineralized matrix that forms the lacunar-canalicular system (LCS). ${ }^{13-15}$ The primary function of LCS is to help osteocytes to obtain nutrients, sense mechanical stimuli, and communicate with other cells via molecular signaling. ${ }^{10}$ The osteocyte LCS is believed to control both "outside-in" (mechanosensing) and "inside-out" (signaling molecule transport) processes. ${ }^{10,16}$ Morphological alterations in LCS could impact the "outside-in" mechanosensing processes by modulating the levels of mechanical stimulus (fluid shear stresses ${ }^{17}$ and drag forces ${ }^{16}$ ). The level of mechanical stimuli is related to osteocyte apoptosis which promotes osteoclastogenesis and is a mechanism by which osteocytes regulate bone adaptation. ${ }^{18,19}$ It is presumable that the osteocyte mechanotransduction-mediated bone adaptation might be affected by altered osteocyte LCS network in T2DM.

Osteocytes remodel its surrounding bone matrix by secreting several proteases, which include matrix metalloproteinase (MMP) 2, MMP13, and cathepsin $\mathrm{K} .{ }^{20} \mathrm{MMPs}$ and tissue inhibitors of MMPs (TIMPs) regulate bone development and remodeling. As a family of proteolytic enzymes, MMPs may hydrolyze ECM. ${ }^{21,22}$ Most MMP members have been detected in bone and mediate bone homeostasis. ${ }^{23,24}$ Both low fracture toughness and low post-yield deflection have been reported in $\mathrm{MMP9}^{-1-}$ mouse femurs. ${ }^{25} \mathrm{MMP} 2$ is mainly secreted by mature osteoblasts and may be a key enzyme involved in bone quality. ${ }^{26,27}$ The precise coordination of TIMPs and MMPs maintains ECM homeostasis, and a TIMP/MMP imbalance adversely affects ECM, leading to bone diseases such as primary osteoporosis, osteoarthritis, and rheumatoid arthritis. ${ }^{25,28,29}$ TIMPs are the natural inhibitor of many MMPs, are widely expressed in bone, and play an essential role in bone adaptation. ${ }^{30}$ TIMP-1 is a soluble glycoprotein of $28 \mathrm{kDa}$ and a prominent member of the TIMP family. It can inhibit most MMPs, except membrane typeMMPs and MMP24. ${ }^{31,32}$ Haeusler et $\mathrm{al}^{33}$ observed that TIMP-1 was present in all zones of the growth plate, osteoblasts, and osteoclasts, some of osteocytes. It also has been reported that TIMP-1 can directly stimulate the bone resorbing activity independent of their inhibition of MMPs at certain physiological concentrations. ${ }^{29}$ Prior studies have investigated the role of TIMP-1 in osteoblasts and/or osteoclasts, ${ }^{29,34,35}$ but little is known about associations between TIMP-1 and the osteocyte network, and its influences on bone quality in T2DM. It is not known whether TIMP-1 located in the LCS is involved in bone fragility in T2DM patients.

\section{Hypothesis}

MMPs are a large family of zinc-dependent ECMdegrading enzymes and play a crucial role in bone matrix remodeling, thus dramatically affecting bone mechanical and material properties. ${ }^{24,36,37}$ TIMPs inhibit the activity of MMPs. ${ }^{34,38}$ Bone quality is dependent on a balance between TIMPs and MMPs. Among four types of TIMPs found in bone, only significant changes in TIMP-1 have reported in the serum of individuals with T2DM. ${ }^{39-41}$ Several studies indicate that osteocytes can express TIMP-1. ${ }^{26,34,42,43}$ The osteocyte LCS plays a vital role in mechanical sensing, strain experience, bone composition, and bone quality. ${ }^{13}$ MMP13 influences perilacunar/canalicular remodeling (PLR), ${ }^{36}$ so interaction between TIMP-1 and MMP13 or other MMPs may improve PLR in pathological conditions. We hypothesized that TIMP-1 located in the osteocyte LCS is involved in T2DM-associated bone fragility (Figure 1).

\section{Evaluation of the hypothesis Altered TIMP-I Level in the Plasma/ Serum of T2DM Patients}

To our knowledge, the underlying mechanisms that lead to the changes of TIMP-1 in plasma/serum of T2DM patients remain scarce; but the positive association between TIMP1 and T2DM in patients concur with the results from several case control and cross-sectional studies (Table 1). In case-control study nested within a prospective cohort among Chinese living in Singapore, Wang et $\mathrm{al}^{40}$ demonstrated that serum TIMP-1 levels were significantly higher in T2DM patients $(n=254)$ than in age and gender-matched non-diabetic patients $(\mathrm{n}=254)$, and elevated TIMP-1 levels were positively associated with T2DM risk. Lee et $\mathrm{al}^{39}$ reported that plasma levels of TIMP-1 and MMP2 were elevated in Korea T2DM patients (without uremia) whereas there was no significant alteration in MMP9 (cases $n=80$, controls $n=80$ ), and the increase in TIMP-1 and MMP2 were independent of age, duration of diabetes, 


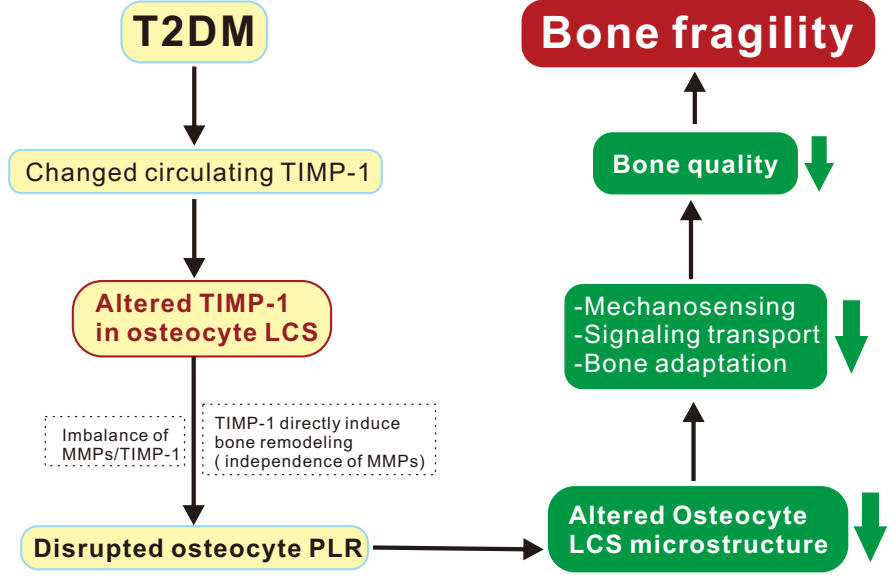

Figure I A conceptual framework of this hypothesis: TIMP-I at sites of osteocyte lacunar-canalicular system (LCS) is partially involved in type 2 diabetes bone fragility. The two potential mechanisms by which TIMP-I in LCS alters PLR are shown in the dotted boxes, and future studies are warranted to elucidate the precise mechanism for this hypothesis.

blood pressure, and blood lipids. Tayebjee et al ${ }^{44}$ showed that circulating MMP-9, TIMP-1 are raised in treated hypertensive T2DM patients from the UK $(n=86)$ compared with normotensive control subjects $(n=63)$. Sundström et $\mathrm{al}^{45}$ presented their interesting data from the USA that plasma TIMP-1 was higher in men compared with women, and increased with age, and positively related to diabetes. However, Papazafiropoulou et $\mathrm{al}^{41}$ reported that serum TIMP-1 was lower in patients with T2DM, and that they exhibited no differences in MMP2 or MMP9. In another study, serum MMP9 was increased in patients with diabetic retinopathy, but there was no

Table I Summary of Association Between TIMP-I Level in Blood and T2DM in Patients

\begin{tabular}{|c|c|c|c|c|c|}
\hline \multirow[t]{2}{*}{ Reference } & \multicolumn{3}{|c|}{ Subjects } & \multirow{2}{*}{$\begin{array}{l}\text { Outcome of TIMP-I } \\
\qquad(\mathrm{ng} / \mathrm{mL})\end{array}$} & \multirow{2}{*}{$\begin{array}{c}\text { Association of TIMP-I } \\
\text { and T2DM }\end{array}$} \\
\hline & Numbers & $\begin{array}{c}\text { Age } \\
\text { (Years) }\end{array}$ & Country & & \\
\hline Wang Y. et al, $2020^{40}$ & $\begin{array}{l}\text { Patients: } 254 \\
\text { Control: } 254\end{array}$ & $\begin{array}{c}59 \pm 5.83 \\
59.3 \pm 6.03\end{array}$ & Singapore ${ }^{a}$ & $\begin{array}{l}227.9 \pm 39 * \\
213.5 \pm 35.6 \\
\text { (Serum Level) }\end{array}$ & Positive \\
\hline Lee SW. et al, $2005^{39}$ & $\begin{array}{l}\text { Patients: } 80 \\
\text { Control: } 80\end{array}$ & $\begin{array}{l}49.9 \pm 9.9 \\
47.4 \pm 7.9\end{array}$ & Korea & $\begin{array}{l}362.1 \pm \mid 87.7 * \\
|72.5 \pm| 84 . \mid \\
\text { (Plasma level) }\end{array}$ & Positive \\
\hline $\begin{array}{l}\text { Tayebjee M.H. et al, } \\
2004^{44}\end{array}$ & $\begin{array}{l}\text { Patients: } 86 \\
\text { Control: } 63\end{array}$ & $\begin{array}{c}68 \pm 6 \\
66 \pm 10\end{array}$ & UK & $\begin{array}{l}397(300-496) * \\
280(225-305) \\
\text { (Plasma level) }\end{array}$ & Positive \\
\hline Sundstrom J. et al, $2004^{45}$ & $\begin{array}{c}\text { Whole samples: } 1069 \text {, } \\
\text { Diabetes: } 9 \%\end{array}$ & $56.3 \pm 9.9$ & USA & $\begin{array}{l}\mathrm{I} .03^{\mathrm{b}},(\mathrm{p}=0.04) * \\
(\text { Plasma level) }\end{array}$ & Positive \\
\hline $\begin{array}{l}\text { Papazafiropoulou A. et al, } \\
2010^{41}\end{array}$ & $\begin{array}{l}\text { Patients: } 60 \\
\text { Control: } 60\end{array}$ & $\begin{array}{c}60.3 \pm 7.4 \\
59.2 \pm 10.1\end{array}$ & Greece & $\begin{array}{l}197.5 \pm 76.5 * \\
233.6 \pm 61.4 \\
\text { (Plasma level) }\end{array}$ & Negative \\
\hline Jayashree K. et al, $2018^{46}$ & $\begin{array}{l}\text { Patients: } 4 \mathrm{I} \\
\text { Control: } 4 \mathrm{I}\end{array}$ & $35-65$ & India & $\begin{array}{l}454.40(359-529) \\
432.8(295.3-539.35) \\
(\text { Plasma level, } p=0.337)\end{array}$ & No significant difference \\
\hline
\end{tabular}

Note: ${ }^{a}$ The Chinese population in Singapore; ${ }^{\mathrm{b}}$ Ratio of plasma level TIMP-I between diabetes and control subjects; $* \mathrm{P}<0.05$ was taken as statistically significant. 
significant difference in TIMP-1 between diabetic retinopathy patients and controls. ${ }^{46}$ The heterogeneous results could be explained by the different characteristics of patients. Compared with the other studies, patients in Papazafiropoulou's study were at more advanced stage of T2DM, and may have received more intensive treatment. ${ }^{41}$ The diabetes therapy have shown to decrease TIMP-1 levels significantly. ${ }^{44}$ Collectively these studies indicate that serum TIMP-1 levels are altered in T2DM patients.

\section{Altered Osteocyte Network in T2DM}

Osteocytes play an essential role in regulating bone homeostasis. The osteocyte LCS plays a critical role in mechanical sensing and transduction, thus affecting the osteocyte function. ${ }^{12,16}$ Mabilleau et $\mathrm{al}^{11}$ reported that profound alterations of osteocyte network was present in a mouse model of high fat-induced type 2 diabetes, and perilacunar mineralization heterogeneity was reduced by $48 \%$, but the mean perilacunar mineralization remained unchanged. Villarino et al ${ }^{47}$ reported reduced lacunar density of alveolar bone in acute streptozotocin-induced diabetic rats. de Mello-Sampayo et $\mathrm{al}^{48}$ described both lacunar density and tibial cortical bone size in 5-month-old streptozotocininduced diabetic rats, but did not provide quantitative confirmation. Ay et $\mathrm{al}^{49}$ reported that lacunar density increased in diabetic rats, and osteocyte territorial matrix decreased. Notably, however, Kerckhofs et $\mathrm{al}^{50}$ reported that there were no significant differences in lacunar density or porosity between mice with obesity-driven T2DM and control mice. The discrepancy presented in the effect of T2DM on osteocyte network can be explained by the diversity of the diabetes models used as well as by the differences between the analysis techniques. Apart from dendritic network connectivity and lacunar density in T2DM bone, the pericellular matrix should be considered because the surface area of the osteocyte LCS within bone is several orders of magnitude greater than the area of the bone surface. ${ }^{12}$ Altered osteocyte connectivity and LCS network could be the critical factors of T2DM bone fragility.

\section{TIMP-I Expressed by Osteocytes}

TIMP-1 can be expressed in osteoblasts, osteoclasts, or lining cells of the various bone tissues, including rib bone, ectopic bone, and osteophytes, and is expressed differently in different physiological and pathological conditions. ${ }^{43}$ Several studies have indicated that osteocytes secrete TIMP-1. In an in situ hybridization study Hatori et $\mathrm{al}^{26}$ reported that TIMP-1 can be expressed in osteoblasts and osteocytes. Prideaux et $\mathrm{al}^{42}$ reported that MLO-A5 cells (an osteoid preosteocyte-like cell) secrete TIMP-1 and MMPs, and that TIMP-1 expression was decreased during the mineralization of MLO-A5, along with MMP2, MMP23, and MMP28. These prior observations suggest that TIMP-1 may be secreted by osteocytes and may be involved in the mineralization of bone matrix. In addition, the molecular weight of TIMP-1 $(\sim 28 \mathrm{kDa})$ is smaller than the sieving cutoff for the LCS $(\sim 70 \mathrm{kDa}),{ }^{51,52}$ indicating that TIMP-1 produced by osteocytes is capable of reaching target cells such as osteoblasts and osteoclasts. Future studies are warranted to elucidate the mechanisms by which type 2 diabetes could alter the expression of TIMPs in osteocytes or other bone cells.

\section{TIMP-I/MMPs Participate in Osteocytic PLR}

As terminally differentiated cell, osteocytes reside in the bone matrix, and have functions similar to osteoclasts with respect to secreting specific molecules that affect local bone matrix remodeling, called osteocyte PLR. In this process osteocytes can directly resorb and replace the local bone ECM. Some members of the MMP family play an important role in PLR, such as MMP2, MMP13 and MMP14. An absence of MMP2 reported had negative effects on bone structure, including destruction of the bone canalicular network, reduced BMD, and increased cortical porosity in long bones. ${ }^{25,53}$ TIMP-1 is a natural inhibitor of MMPs. It has been reported that mesenchymal stem cells can inhibit MMP2 by secreting TIMP-1, and TIMP-1 can inhibit the activation of MMP2 under pathological conditions and protect blood vessels from protease damage. ${ }^{54}$ These studies provoke a question as to whether the inhibitory effects of TIMP1 on MMP2 under physiological or pathological conditions can affect the osteocyte lacunar-canalicular network. MMP13 is essential for remodeling the lacunarcanalicular pericellular matrix. MMP13 deficiency may impair the osteocyte network, collagen, and mineral tissue. $^{36,55}$ MMP2 and MMP9 can be activated by MMP13; and MMP13 deficiency may alter MMP2 and MMP9 activity, interrupting bone remodeling. ${ }^{22}$ TIMP-1 can bind strongly to MMP13, downregulating its activity. ${ }^{56}$ Inhibiting MMP13 activity can affect pericellular matrix remodeling. Given the importance of TIMP1 in the remodeling of bone matrix and the lacunar 
canalicular network, further research should be done to elucidate the effects of TIMP-1 on bone tissue and the function of TIMP-1 on bone quality in T2DM. The reported parameter of osteocyte lacunae density in diabetes bone is inconsistent, and the altered osteocyte dendritic network connectivity has been confirmed. Geoffroy et $\mathrm{al}^{57}$ reported that overexpression of TIMP-1 in osteoblast-lineage cells did not affect osteocyte lacunae (number density at tissue level in bone). Therefore, altered TIMP-1 level may affect osteocyte pericellular matrix, not the lacunae density at the whole bone tissue level. Impaired osteocyte pericellular matrix by TIMP-1 may be involved in bone fragility of T2DM in which changes of TIMP-1 has been reported.

\section{Conclusions}

Skeletal fracture is a devastating event with dismal health consequences. Individuals with T2DM are associated with an increased risk of bone fracture. By several literature evidence and our view point, it is possible that TIMP-1 may have a specific role in the mechanism of bone fragility associated with T2DM. Prior research indicates that TIMP-1 may regulate the LCS pericellular matrix by inhibiting MMPs, and serum TIMP-1 levels are changed in T2DM patients. It is not clear what role does TIMP-1 play in the development of bone fragility in T2DM. Confirming the specific location and local roles of TIMP-1 in the osteocyte LCS may better explain the mechanism of bone fragility associated with $\mathrm{T} 2 \mathrm{DM}$, and provide a target for preventing bone fragility in T2DM patients.

\section{Funding}

This work was supported by the National Natural Science Foundation of China (11602046, 82070899), the Science and Technology Research Program of Chongqing Municipal Education Commission (KJQN201900418, KJQN202000421), the Project of Science and Technology of Chongqing Yuzhong District (20190114).

\section{Disclosure}

The authors declare no conflicts of interest.

\section{References}

1. Janghorbani M, Van Dam RM, Willett WC, Hu FB. Systematic review of type 1 and type 2 diabetes mellitus and risk of fracture. $\mathrm{Am}$ J Epidemiol. 2007;166(5):495-505. doi:10.1093/aje/kwm106

2. Wang H, Ba Y, Xing Q, Du JL. Diabetes mellitus and the risk of fractures at specific sites: a meta-analysis. BMJ Open. 2019;9(1): e024067. doi:10.1136/bmjopen-2018-024067
3. Yamamoto M, Yamaguchi T, Yamauchi M, Kaji H, Sugimoto T. Diabetic patients have an increased risk of vertebral fractures independent of BMD or diabetic complications. $J$ Bone Miner Res. 2009;24(4):702-709. doi:10.1359/jbmr.081207

4. Schwartz AV, Vittinghoff E, Bauer DC, et al. Association of BMD and FRAX score with risk of fracture in older adults with type 2 diabetes. JAMA. 2011;305(21):2184-2192.

5. Vestergaard P. Discrepancies in bone mineral density and fracture risk in patients with type 1 and type 2 diabetes-a meta-analysis. Osteoporos Int. 2007;18(4):427-444.

6. Hunt HB, Torres AM, Palomino PM, et al. Altered tissue composition, microarchitecture, and mechanical performance in cancellous bone from men with type 2 diabetes mellitus. $J$ Bone Miner Res. 2019;34(7):1191-1206.

7. Karim L, Moulton J, Van Vliet M, et al. Bone microarchitecture, biomechanical properties, and advanced glycation end-products in the proximal femur of adults with type 2 diabetes. Bone. 2018;114:32-39.

8. Eckhardt BA, Rowsey JL, Thicke BS, et al. Accelerated osteocyte senescence and skeletal fragility in mice with type 2 diabetes. JCI Insight. 2020;5(9):e135236.

9. Liu X, Li W, Cai J, et al. Spatiotemporal characterization of microdamage accumulation and its targeted remodeling mechanisms in diabetic fatigued bone. FASEB J. 2020;34(2):2579-2594.

10. Lai X, Price C, Modla S, et al. The dependences of osteocyte network on bone compartment, age, and disease. Bone Res. 2015;3(1):1. doi:10.1038/boneres.2015.9.

11. Mabilleau G, Perrot R, Flatt PR, Irwin N, Chappard D. High fat-fed diabetic mice present with profound alterations of the osteocyte network. Bone. 2016;90:99-106. doi:10.1016/j.bone.2016.06.008

12. Bonewald LF. The amazing osteocyte. J Bone Miner Res. 2011;26 (2):229-238. doi:10.1002/jbmr.320

13. Vahidi G, Rux C, Sherk VD, Heveran CM. Lacunar-canalicular bone remodeling: impacts on bone quality and tools for assessment. Bone. 2021;143:115663. doi:10.1016/j.bone.2020.115663

14. van Tol AF, Schemenz V, Wagermaier W, et al. The mechanoresponse of bone is closely related to the osteocyte lacunocanalicular network architecture. Proc Natl Acad Sci USA. 2020;117 (51):32251-32259. doi:10.1073/pnas.2011504117

15. Qing H, Bonewald LF. Osteocyte remodeling of the perilacunar and pericanalicular matrix. Int J Oral Sci. 2009;1(2):59-65. doi:10.4248/ ijos.09019

16. Wang B, Lai X, Price C, et al. Perlecan-containing pericellular matrix regulates solute transport and mechanosensing within the osteocyte lacunar-canalicular system. J Bone Miner Res. 2014;29(4):878-891. doi: $10.1002 / \mathrm{jbmr} .2105$

17. Weinbaum S, Cowin SC, Zeng Y. A model for the excitation of osteocytes by mechanical loading-induced bone fluid shear stresses. J Biomech. 1994;27(3):339-360. doi:10.1016/00219290(94)90010-8

18. Wang B, Zhou X, Price C, Li W, Pan J, Wang L. Quantifying load-induced solute transport and solute-matrix interaction within the osteocyte lacunar-canalicular system. $J$ Bone Miner Res. 2013;28(5):1075-1086. doi:10.1002/jbmr.1804

19. Wang B, Sun X, Akkus O, Wang L. Elevated solute transport at sites of diffuse matrix damage in cortical bone: implications on bone repair. J Orthop Res. 2018;36(2):692-698. doi:10.1002/jor.23742

20. Yee CS, Schurman CA, White CR, Alliston T. Investigating osteocytic perilacunar/canalicular remodeling. Curr Osteoporos Rep. 2019;17(4):157-168. doi:10.1007/s11914-019-00514-0

21. Klein T, Bischoff R. Physiology and pathophysiology of matrix metalloproteases. Amino Acids. 2011;41(2):271-290. doi:10.1007/ s00726-010-0689-x

22. Paiva KB, Granjeiro JM. Bone tissue remodeling and development: focus on matrix metalloproteinase functions. Arch Biochem Biophys. 2014;561:74-87. doi:10.1016/j.abb.2014.07.034 
23. Krane SM, Inada M. Matrix metalloproteinases and bone. Bone. 2008;43(1):7-18. doi:10.1016/j.bone.2008.03.020

24. Paiva KBS, Granjeiro JM. Matrix metalloproteinases in bone resorption, remodeling, and repair. Prog Mol Biol Transl Sci. 2017;148:203-303. doi:10.1016/bs.pmbts.2017.05.001

25. Nyman JS, Lynch CC, Perrien DS, et al. Differential effects between the loss of MMP-2 and MMP-9 on structural and tissue-level properties of bone. J Bone Miner Res. 2011;26(6):1252-1260. doi:10.1002/ jbmr.326

26. Hatori K, Sasano Y, Takahashi I, Kamakura S, Kagayama M, Sasaki K. Osteoblasts and osteocytes express MMP2 and -8 and TIMP1, -2 , and -3 along with extracellular matrix molecules during appositional bone formation. Anat Rec A Discov Mol Cell Evol Biol. 2004;277(2):262-271. doi:10.1002/ar.a.20007

27. Luo XH, Guo LJ, Shan PF, et al. Relationship of circulating MMP-2, MMP-1, and TIMP-1 levels with bone biochemical markers and bone mineral density in postmenopausal Chinese women. Osteoporos Int. 2006;17(4):521-526. doi:10.1007/s00198-005-0017-6

28. Schiltz C, Marty C, de Vernejoul MC, Geoffroy V. Inhibition of osteoblastic metalloproteinases in mice prevents bone loss induced by oestrogen deficiency. J Cell Biochem. 2008;104(5):1803-1817.

29. Sobue T, Hakeda Y, Kobayashi Y, et al. Tissue inhibitor of metalloproteinases 1 and 2 directly stimulate the bone-resorbing activity of isolated mature osteoclasts. $J$ Bone Miner Res. 2001;16 (12):2205-2214. doi:10.1359/jbmr.2001.16.12.2205

30. Bord S, Horner A, Hembry RM, Reynolds JJ, Compston JE. Distribution of matrix metalloproteinases and their inhibitor, TIMP-1, in developing human osteophytic bone. J Anat. 1997;191 (Pt 1):39-48.

31. Barthelemi S, Robinet J, Garnotel R, et al. Mechanical forces-induced human osteoblasts differentiation involves MMP-2/ MMP-13/MT1-MMP proteolytic cascade. J Cell Biochem. 2012;113 (3):760-772.

32. Baker AH, Edwards DR, Murphy G. Metalloproteinase inhibitors: biological actions and therapeutic opportunities. J Cell Sci. 2002;115 (Pt 19):3719-3727.

33. Haeusler G, Walter I, Helmreich M, Egerbacher M. Localization of matrix metalloproteinases, (MMPs) their tissue inhibitors, and vascular endothelial growth factor (VEGF) in growth plates of children and adolescents indicates a role for MMPs in human postnatal growth and skeletal maturation. Calcif Tissue Int. 2005;76 (5):326-335.

34. Xi Y, Huang H, Zhao Z, Ma J, Chen Y. Tissue inhibitor of metalloproteinase 1 suppresses growth and differentiation of osteoblasts and differentiation of osteoclasts by targeting the AKT pathway. Exp Cell Res. 2020;389(2):111930.

35. Egea V, Zahler S, Rieth $\mathrm{N}$, et al. Tissue inhibitor of metalloproteinase-1 (TIMP-1) regulates mesenchymal stem cells through let-7f microRNA and Wnt/beta-catenin signaling. Proc Natl Acad Sci U S A. 2012;109(6):E309-316.

36. Tang SY, Herber RP, Ho SP, Alliston T. Matrix metalloproteinase-13 is required for osteocytic perilacunar remodeling and maintains bone fracture resistance. J Bone Miner Res. 2012;27(9):1936-1950.

37. Liang HPH, Xu J, Xue M, Jackson C. Matrix metalloproteinases in bone development and pathology: current knowledge and potential clinical utility. Metalloproteinases Med. 2016;3:93-102.

38. Brew K, Nagase H. The tissue inhibitors of metalloproteinases (TIMPs): an ancient family with structural and functional diversity. Biochim Biophys Acta. 2010;1803(1):55-71.

39. Lee SW, Song KE, Shin DS, et al. Alterations in peripheral blood levels of TIMP-1, MMP-2, and MMP-9 in patients with type-2 diabetes. Diabetes Res Clin Pract. 2005;69(2):175-179.
40. Wang Y, Yuan JM, Pan A, Koh WP. Tissue inhibitor matrix metalloproteinase 1 and risk of type 2 diabetes in a Chinese population. BMJ Open Diabetes Res Care. 2020;8(1):e001051.

41. Papazafiropoulou A, Perrea D, Moyssakis I, Kokkinos A, Katsilambros N, Tentolouris N. Plasma levels of MMP-2, MMP-9 and TIMP-1 are not associated with arterial stiffness in subjects with type 2 diabetes mellitus. J Diabetes Complications. 2010;24 (1):20-27.

42. Prideaux M, Staines KA, Jones ER, Riley GP, Pitsillides AA, Farquharson C. MMP and TIMP temporal gene expression during osteocytogenesis. Gene Expr Patterns. 2015;18(1-2):29-36.

43. Bord S, Horner A, Beeton CA, Hembry RM, Compston JE. Tissue inhibitor of matrix metalloproteinase-1 (TIMP-1) distribution in normal and pathological human bone. Bone. 1999;24(3):229-235.

44. Tayebjee MH, Lim HS, MacFadyen RJ, Lip GY. Matrix metalloproteinase- 9 and tissue inhibitor of metalloproteinase- 1 and -2 in type 2 diabetes: effect of 1 year's cardiovascular risk reduction therapy. Diabetes Care. 2004;27(8):2049-2051.

45. Sundstrom J, Evans JC, Benjamin EJ, et al. Relations of plasma total TIMP-1 levels to cardiovascular risk factors and echocardiographic measures: the Framingham heart study. Eur Heart J. 2004;25 (17):1509-1516.

46. Jayashree K, Yasir M, Senthilkumar GP, Ramesh Babu K, Mehalingam V, Mohanraj PS. Cculating matrix modulators (MMP-9 and TIMP-1) and their association with severity of diabetic retinopathy. Diabetes Metab Syndr. 2018;12(6):869-873.

47. Villarino ME, Sánchez LM, Bozal CB, Ubios AM. Influence of short-term diabetes on osteocytic lacunae of alveolar bone. A histomorphometric study. Acta Odontol Latinoam. 2006;19 (1):23-28.

48. de Mello-sampayo C, Agripino AA, Stilwell D, et al. Chronic hyperglycemia modulates rat osteoporotic cortical bone microarchitecture into less fragile structures. Int J Endocrinol. 2017;2017:4603247.

49. Ay B, Parolia K, Liddell RS, et al. Hyperglycemia compromises rat cortical bone by increasing osteocyte lacunar density and decreasing vascular canal volume. Commun Biol. 2020;3(1):20.

50. Kerckhofs G, Durand M, Vangoitsenhoven R, et al. Changes in bone macro- and microstructure in diabetic obese mice revealed by high resolution microfocus X-ray computed tomography. Sci Rep. 2016;6:35517.

51. Dallas SL, Prideaux M, Bonewald LF. The osteocyte: an endocrine cell ... and more. Endocr Rev. 2013;34(5):658-690.

52. Knothe Tate ML, Niederer P, Knothe U. In vivo tracer transport through the lacunocanalicular system of rat bone in an environment devoid of mechanical loading. Bone. 1998;22(2):107-117.

53. Inoue K, Mikuni-Takagaki Y, Oikawa K, et al. A crucial role for matrix metalloproteinase 2 in osteocytic canalicular formation and bone metabolism. J Biol Chem. 2006;281(44):33814-33824.

54. Lozito TP, Tuan RS. Mesenchymal stem cells inhibit both endogenous and exogenous MMPs via secreted TIMPs. J Cell Physiol. 2011;226(2):385-396.

55. Mazur CM, Woo JJ, Yee CS, et al. Osteocyte dysfunction promotes osteoarthritis through MMP13-dependent suppression of subchondral bone homeostasis. Bone Res. 2019;7:34.

56. Wang M, Sampson ER, Jin H, et al. MMP13 is a critical target gene during the progression of osteoarthritis. Arthritis Res Ther. 2013;15 (1):R5.

57. Geoffroy V, Marty-Morieux C, Le Goupil N, et al. In vivo inhibition of osteoblastic metalloproteinases leads to increased trabecular bone mass. J Bone Miner Res. 2004;19(5):811-822. 


\section{Publish your work in this journal}

Diabetes, Metabolic Syndrome and Obesity: Targets and Therapy is an international, peer-reviewed open-access journal committed to the rapid publication of the latest laboratory and clinical findings in the fields of diabetes, metabolic syndrome and obesity research. Original research, review, case reports, hypothesis formation, expert opinion and commentaries are all considered for publication. The manuscript management system is completely online and includes a very quick and fair peer-review system, which is all easy to use. Visit http://www.dovepress.com/testimonials.php to read real quotes from published authors. 